Dossiê - Para além do “ativismo judicial" e da “judicialização da política" DOI: $10.5433 / 2176-6665.2016 \mathrm{v} 21 \mathrm{~N} 1 \mathrm{P} 103$

\title{
Qual a Classe, A COR E O GÊnero da JUSTIÇA? REFlexões SOBRE AS (IM)POSSIBILIDADES DE COMBATE À VIOLÊNCIA DOMÉSTICA E FAMILIAR CONTRA AS MULHERES NEGRAS PELO PODER JUDICIÁRIO BRASILEIRO
}

\author{
Tatyane Guimarães Oliveira ${ }^{1}$
}

\begin{abstract}
Resumo
Forçado a se pronunciar sobre problemas sociais antes ignorados, o Poder Judiciário tem sido desafiado a atuar na proteção de grupos historicamente excluídos e reconhecer a existência das desigualdades raciais, sociais, econômicas e de gênero. Neste contexto, o presente trabalho propõe lançar algumas reflexões sobre as (im) possibilidades de combate à violência doméstica e familiar contra as mulheres negras por parte do Poder Judiciário Brasileiro, considerando os marcadores sociais de raça, gênero e classe e os dados apresentados no Mapa da Violência 2015 - Homicídio de Mulheres no Brasil. O mito da democracia racial ainda tem fortes impactos na invisibilidade da questão junto ao Sistema de Justiça e influencia consideravelmente a recusa deste em olhar de forma mais atenta para as mulheres negras no âmbito da violência doméstica e familiar.
\end{abstract}

Palavras-chave: Interseccionalidade. Poder Judiciário. Violência Doméstica. Feminismo Negro.

1 Doutoranda no Programa de Pós-Graduação em Estudos Interdisciplinares sobre mulheres, gênero e feminismos da Universidade Federal da Bahia (PPGNEIM/UFBA) e professora do Departamento de Ciências Jurídicas da Universidade Federal da Paraíba (UFPb), Brasil. tatygut@gmail.com 


\title{
What's The Class, Color And Gender Of Justice? Reflections On The (Im)Possibilities To Combat Domestic Violence Against Black Women In The Brazilian Judicial System
}

\begin{abstract}
FORCED TO face social problems previously ignored, the Judicial System has been challenged to act in the protection of historically excluded groups and recognize the existence of racial, social, economic and gender inequalities. In this context, this paper proposes to launch some reflections on the (im) possibilities in combating domestic violence against black women by the Court System in Brazil, considering the social markers of race, gender and class and the results of the research Map Violence 2015 - Murder of Women in Brazil. The myth of racial democracy still has a strong impact on the invisibility of the issue with the Judiciary and greatly influences on the refusal to a attentive look on domestic violence against black women.
\end{abstract}

Keywords: Intersectionality. Judiciary. Domestic Violence. Black Feminism.

\section{INTRODUÇÃo}

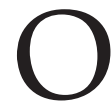

Poder Judiciário é uma instituição composta por agentes comprometidos política e ideologicamente com as crenças que moldam seu modo de encarar a vida social. Vivemos em uma sociedade marcada pela discriminação de gênero, raça, classe, geração e outras formas de exclusão e o Poder Judiciário, apesar dos princípios que regem seu funcionamento, tem atuado em consonância com esses mesmos valores. O Poder Judiciário no Brasil tem cor, gênero e classe social.

A sociedade brasileira forma-se com base em ideias de liberdade e igualdade orientadas por princípios liberais escravocratas, individualistas e contratualistas e tem negado sistematicamente as perspectivas que apontem para uma democracia radical. Essa negação se ancora especialmente em ideias que definem uma dinâmica social, 
econômica e política própria de uma sociedade de castas, com o estabelecimento de condições de acesso aos direitos que limitam as chances de ascensão social de alguns grupos (COSTA, 2006, p. 195).

$\mathrm{Na}$ mesma direção se dão as ações do Estado, que atua geralmente em consonância com essas ideologias, mas que tem sido forçado a mudar consideravelmente suas perspectivas na efetivação dos direitos de grupos historicamente excluídos por uma série de fatores políticos, sociais e econômicos, dentre estes as ações e impactos dos movimentos sociais nas últimas décadas no campo da incidência política, controle e participação social.

Ao Poder Judiciário podem-se atribuir as mesmas reflexões. Possuindo a função de resolver conflitos sociais, inclusive aqueles que envolvem o próprio Estado, tem como alicerce princípios como a neutralidade, imparcialidade e a justiça. Todavia, essa crença na possibilidade de tomar decisões e realizar atividades desconsiderando a existência dos posicionamentos políticos e ideológicos que permeiam toda e qualquer ação no mundo, e de que essa perspectiva é a que tem maior capacidade de ser justa, tem sido a mola propulsora para um vasto campo de violações de direitos e de uso estratégico dessa estrutura do Estado por grupos específicos com fins de manutenção de privilégios.

A proposta do presente trabalho é realizar uma reflexão sobre a atuação do Poder Judiciário na proteção de mulheres em situação de violência, considerando os marcadores sociais de raça, gênero e classe. Parte da perspectiva de que esse espaço de atuação é importante para a efetivação dos direitos de populações historicamente vulnerabilizadas pela exclusão social e que sua ocupação e a subversão dos valores que ainda o dominam devem fazer parte das estratégias de luta contra o capitalismo, o racismo, o patriarcado e as desigualdades sociais que tem (re)produzido. Essa politização do Poder Judiciário torna-se essencial para que seu papel seja subvertido em benefício das lutas 
sociais e do combate às opressões que atingem a sociedade brasileira (DALLARI, 2007; WOLKMER, 2003).

Proponho uma discussão acerca dos desafios que estão colocados ao Poder Judiciário na proteção das mulheres negras em situação de violência doméstica e familiar considerando as dinâmicas entre raça, classe e gênero e a invisibilidade que é construída por parte das instituições e da sociedade em relação ao fenômeno, em detrimento das denúncias trazidas pelo movimento de mulheres negras no Brasil. As reflexões aqui propostas serão realizadas com base em dados relacionados à violência doméstica e familiar contra a mulher, especificamente os divulgados no Mapa da Violência 2015: Homicídio de Mulheres no Brasil (WAISELFISZ, 2015), que reafirmam as históricas denúncias das mulheres negras em torno das diferentes intensidades e dinâmicas das violências que as atingem e as resistência do Estado em reconhecê-las.

\section{Perspectivas do feminismo negro sobre as artimanhas dos sistemas:} VIOLÊNCIAS (RE)PRODUZIDAS PELO CAPITALISMO, RACISMO E PATRIARCADO

Ao trabalhar os dados relativos à violência doméstica e familiar contra as mulheres negras, é preciso situar conceitualmente os marcadores que são essenciais para a reflexão do presente trabalho. Articular reflexões nesse campo é propor diálogos com categorias importantes para uma perspectiva de análise que dê conta da complexidade do fenômeno. Raça, gênero e classe, enquanto marcadores sociais que envolvem os fenômenos de violência, são conceitos que precisam ser situados nos campos analítico, histórico e político.

É a perspectiva lançada por Scott (1990, p. 75), ao trabalhar o gênero como uma categoria útil de análise histórica, que contribui para a compreensão de algumas reflexões importantes para o debate aqui 
proposto. Questionando a busca de uma causalidade geral e universal das coisas, a autora afirma que se deve buscar uma explicação baseada no significado e que para buscar esse significado deve-se lidar com o sujeito individual, assim como a organização social, articulando a natureza de suas inter-relações. Para isso propõe a utilização de um conceito de poder que, como proposto pelo filósofo Michel Foucault, seja "entendido como constelações dispersas de relações desiguais, discursivamente constituídas em 'campo de forças sociais"' (SCOTT, 1990, p. 86). E nesse raciocínio propõe uma definição de gênero que, dividida em duas partes e seus subconjuntos, deve ser compreendida de forma que estas sejam interrelacionadas, mas analiticamente diferenciadas.

Para Scott (1990, p. 86), portanto, o gênero é um elemento constitutivo de relações sociais baseadas nas diferenças percebidas entre os sexos e uma forma primária de dar significado às relações de poder. Ao propor o uso do gênero como categoria para a análise histórica, Scott pretende "compreender e explicar significativamente o caráter relacional, transversal e variável dessa categoria analítica" (SCAVONE, 2008, p. 179).

Essas categorias precisam ser percebidas e empregadas analiticamente enquanto lentes que possibilitem compreender não só como as relações se constituem, mas como estas se (re)produzem no campo das relações de poder que já são inicialmente significadas de forma a produzir exclusões e que, portanto, se constituem e se constroem com base na desigualdade.

O gênero passa por diversos descolamentos teóricos que se constroem junto a práxis feminista e em ambas as dimensões, prática e acadêmica, as tensões se colocam como necessárias para seu desenvolvimento. Nesse sentido, opto pelo uso de categorias que se aliam às reivindicações dos movimentos feministas no Brasil, como o uso da categoria "mulheres" e outras que se constituem como 
expressões e instrumentos políticos de luta no contexto específico do Brasil.

É preciso problematizar não só como essas identidades são utilizadas para fixar binarismo ou oposições construídas socialmente e tomadas como naturais para justificar as opressões, mas tomá-las enquanto paradoxo como propõe Scott (2005, p. 14), pois, apesar de serem as justificativas da opressão, essas permitem, ao mesmo tempo, a reivindicação de respeito às diversidades e especificidades que precisam de atenção exatamente em face dessa diferenciação negativa (discriminação e violência).

Nesse campo de tensões, é o feminismo negro que coloca aos movimentos feministas, assim como ao movimento negro, os questionamentos necessários para que estes de fato se construam considerando a realidade social de todas as mulheres. Carneiro (2003, p. 118) explica que o feminismo, por muito tempo, foi prisioneiro da visão eurocêntrica e universalizante das mulheres trazendo como consequência a incapacidade de reconhecer as diferenças e as desigualdades presentes no universo feminino a despeito da identidade biológica, silenciando as vozes e os corpos estigmatizados de mulheres atingidas por outras formas de opressão além do sexismo.

$\mathrm{O}$ movimento de mulheres negras se organizou e marcou os movimentos feministas e negro destacando a afirmação de uma identidade feminista e uma identidade negra de forma interseccional, fortalecendo as ações das mulheres negras na luta contra o racismo e o sexismo e proporcionando seu empoderamento e autonomia na conquista de políticas públicas que atendam às suas demandas específicas (CARVALHO; ROCHA, 2012).

Raça torna-se, portanto, uma categoria fundamental, assim como racismo, não só para a compreensão do fenômeno da violência doméstica, como também para as reflexões no campo das ações do Poder Judiciário nesse campo. Para Munanga (2004), apesar da inexistência 
da raça como realidade biológica e científica, essa constatação não foi e não é suficiente para fazer desaparecer as categorias mentais que a sustentam. $\mathrm{O}$ autor destaca que raça é um conceito carregado de ideologia e, enquanto tal, esconde algo não-proclamado, qual seja, a relação de poder e dominação.

Politizando o conceito de raça para que este se constitua em bandeira política de luta contra o racismo, deve-se também perceber a importância da intersecção da raça com o gênero e atentar para as especificidades do racismo que atinge as mulheres negras. Werneck (2010) destaca que o racismo precisa ser compreendido como catalisador das diferentes formas de violência que atingem as mulheres negras, ao mesmo tempo em que deve ser entendido como violência em si mesmo. Destaca que as experiências do racismo variam conforme as condições subjetivas e objetivas das mulheres e que os marcadores que caracterizam essas condições (orientação sexual, identidade de gênero, classe e geração, por exemplo), potencializado pelo racismo, produz formas ou intensidades diferenciadas de violências contra as mulheres negras, ainda que apresentem semelhanças desde a perspectiva de linha de cor.

$\mathrm{Na}$ linha das reflexões aqui lançadas destaca-se que não se trata de somar as três contradições ou de variáveis quantitativas, mas de notar a "realidade compositória e nova que resulta dessa fusão" (SAFFIOTI, 2015, p. 122). No mesmo sentido argumenta Werneck (2010, p. 13) ao resgatar as afirmativas das mulheres negras ao longo do tempo.

O racismo pode ser descrito como patriarcal e capitalista na contemporaneidade, ainda que reconheçamos aspectos ainda mais complexos em seu percurso. E deve ser reconhecido também como forma de violência estrutural que atinge tanto a grandes populações, como a indivíduos em sua singularidade. Esta complexidade permite compreender as afirmativas de que mulher negra é mais do que o somatório de gênero mais raça, vivendo 
algo mais do que dupla ou tripla discriminação, ou que é afrontada por diferentes eixos de subordinação. Indo mais adiante, a mulher negra deve ser vista como uma singularidade (histórica, política cultural e social) sobre quem o racismo patriarcal capitalista incide. E cujas ações de contraponto e superação deste devem ser igualmente singulares, específicas.

É necessário um olhar que aponte a direção para a compreensão de como essas categorias se articulam, para que as respostas não sejam pontuais e marcadas por análises paralelas sobre o fenômeno. Essa é uma questão crucial para que tenhamos uma política que realmente atente para essas intersecções. As políticas públicas voltadas para o combate à violência doméstica, assim como para outras formas de violência de gênero, passam pela atuação do Estado, como não poderia deixar de ser na nossa forma de organização atual. E assim como partem de perspectivas que não reconhecem o racismo como uma realidade, negam também, ou se não negam ignoram, as intersecções entre esses marcadores.

São as mulheres negras, ao exigirem dos movimentos negro e feminista o reconhecimento das especificidades que marcam as variadas formas de opressão que vivenciam, que impulsionam a construção de uma abordagem interseccional dos marcadores das diferenças e desigualdades.

A interseccionalidade é uma conceituação do problema que busca capturar as consequências estruturais e dinâmicas da interação entre dois ou mais eixos da subordinação. Ela trata especificamente da forma pela qual o racismo, o patriarcalismo, a opressão de classe e outros sistemas discriminatórios criam desigualdades básicas que estruturam as posições relativas de mulheres, raças, etnias, classes e outras. Além disso, a interseccionalidade trata da forma como ações e políticas específicas geram opressões que fluem ao longo de tais eixos, constituindo aspectos dinâmicos ou ativos do desempoderamento (CRENSHAW, 2002, p. 177). 
Como alerta Sardenberg (2015) é no contexto da dinâmica das relações sociais e em uma dimensão histórica que estes conceitos devem ser trabalhados, pois essas relações se forjam especificamente em contextos que se situam histórica, social e culturalmente, como é o caso da realidade brasileira. Logo, destaca a autora, as categorias gênero, raça e classe que estruturam a vida das pessoas dependerá inevitavelmente da presença, ou não, de matrizes macroestruturais de opressão como o sexismo, o racismo e capitalismo.

Nos debates sobre as violências contra as mulheres negras, essa percepção é essencial. Mostrando como as relações entre esses marcadores são complexas, Saffioti (2015) aponta que uma série de transformações ocorrem no gênero com a emergência das classes, pois, como os demais fenômenos sociais, o patriarcado está em permanente transformação e ressalta que o racismo se coloca também como estruturante da vida social. A noção de interseccionalidades ganha relevância nesse campo, pois as dinâmicas das relações sociais e as articulações entre as opressões revelam uma complexidade que, se não compreendida nessa mesma medida, acabam resultando análises superficiais e sem capacidade de mobilizar mudanças sociais.

É nesse campo teórico que devem se dar as análises em torno da violência doméstica e familiar contra as mulheres negras, visto ser nítido que o recorte de gênero não é suficiente para a compreensão de toda a extensão do fenômeno e que não se pode generalizar o processo da violência desconsiderando as desigualdades raciais, sociais e econômicas que enfrentam.

(IM)Possibilidades de COMbate À VIOLÊNCIA doMÉSTICA E FAMILIAR contra as mulheres negras pelo Poder Judiciário Brasileiro

Ao contestar as perspectivas universalizantes do feminismo, as mulheres negras lançam desafios no campo do combate à violência 
doméstica e familiar e apontam outra dimensão do problema, qual seja, uma forma específica de violência que atinge o direito à representação positiva e limita as possibilidades de encontro no mercado afetivo (CARNEIRO, 2003).

Nesse sentido, podem ser adotados dois parâmetros de análise sobre a violência contra as mulheres. O primeiro diz respeito às articulações entre raça, classe e gênero nas relações intersubjetivas, ou seja, um entrelaçamento do racismo e da pobreza com a violência de gênero na própria manifestação de violência (CARNEIRO, 2003; PEREIRA, 2013); e o segundo se refere às articulações dos sistemas de opressão na sua manifestação institucional, o que permite analisar essas intersecções no campo do acesso às políticas públicas.

Para este trabalho é o segundo parâmetro que fornece maiores subsídios de análise. A violência doméstica e familiar contra as mulheres e seu enfrentamento se inserem em processos que envolvem o espaço público e a sua conexão com o espaço privado, pois é essa especificidade que os marcam. Essas dinâmicas internas são cruciais para compreender o impacto do fenômeno da violência contra as mulheres negras e o desvelamento e possibilidades de compreensão do fenômeno de forma mais aprofundada constitui condição para o seu enfrentamento (PEREIRA, 2013).

$\mathrm{O}$ reconhecimento dos privilégios das mulheres brancas e da discriminação racial como fatores de produção e reprodução das desigualdades sociais experimentadas pelas mulheres negras são essenciais para a análise do fenômeno da violência doméstica, especialmente no que se refere ao acesso aos mecanismos de proteção colocados à disposição dessas mulheres, mas negados pela estrutura racista do Estado.

É a lei Maria da Penha (LMP) que marca no ordenamento jurídico o reconhecimento dos direitos humanos das mulheres. Sua aprovação é resultado das articulações dos movimentos feministas 
no Brasil e estabelece mecanismos importantes de proteção, como a articulação em rede das instituições de combate à violência doméstica e familiar, medidas de prevenção e assistência, assim como as medidas protetivas de urgência.

Todavia, é preciso atentar para o fato de que as instituições estatais responsáveis pela aplicação e funcionamento desses mecanismos se forjam em valores e ideologias que historicamente (re)produzem exclusões, dentre elas as que vivenciam as mulheres. E ainda sim, mesmo com a existência de políticas públicas especificas, estudos apontam a invisibilização sistemática de outros marcadores de diferença que impactam suas vidas, perceptível, por exemplo, pela escassa produção de dados relacionados à lei Maria da Penha no âmbito dos tribunais (BRASIL, 2014, 2015a; FERREIRA; BARBOSA; OLIVEIRA, 2015) e pelos posicionamentos dos tribunais em questões que envolvem esses marcadores (PIRES, LYRIO, 2016; SANTOS, 2013; SEVERI, 2016).

Os espaços em que as experiências de mulheres étnica e racialmente identificadas são invisibilizadas e marginalizadas tendem a tratar os abusos aos direitos humanos de forma menos efetiva (CRENSHAW, 2002). E é esse o contexto que envolve o Poder Judiciário no Brasil. As recentes análises relacionadas à aplicabilidade da lei Maria da Penha têm demonstrado, apesar de alguns avanços importantes, que a sua aplicação tem sido dificultada por questões que envolvem a indisposição política para o investimento em estrutura e recursos humanos, além de apontar para posicionamentos ideológicos de juízes e juízas que comprometem a proteção das mulheres (BRASIL, 2014, 2015a; FERREIRA; BARBOSA; OLIVEIRA, 2015; GOMES, 2009; PASINATO, 2009).

Outro documento importante para a referência de análise neste trabalho é o Mapa da Violência 2015: Homicídio de Mulheres no Brasil (WAISELFISZ, 2015), versão que apresentou dados relacionados aos 
homicídios de mulheres com recortes anteriormente inexistentes no âmbito de suas pesquisas, como o de raça, a evolução dos homicídios das mulheres e a estimativa de feminicídios.

Outros estudos já vêm apontando o perfil das mulheres que são assassinadas no Brasil, a maioria são negras, nordestinas e possuem baixa escolaridade (GARCIA et al., 2006). Mas os dados apresentados no Mapa da Violência 2015 se mostram relevantes para a análise especialmente por indicarem o aumento considerável do número de homicídios de mulheres em dez anos (2003-2013) com a inclusão do marco de aprovação da Lei Maria da Penha (2006) e por apontarem informações comparativas no que se referem aos homicídios de mulheres negras e brancas.

A fonte básica utilizada pelo Mapa da Violência na análise dos homicídios no país é a do Sistema de Informações de Mortalidade (SIM) da Secretaria de Vigilância em Saúde (SVS) do Ministério da Saúde (MS); as informações foram obtidas a partir das declarações de óbitos que normalmente fornecem dados relacionados a idade, sexo, estado civil, profissão, naturalidade, local de residência, causa da morte e a indicação no caso de agressões intencionais.

O SIM ainda carece de informações acerca da relação entre a vítima e o agressor, assim como os motivos do homicídio (GARCIA et al., 2006) o que dificulta o diagnóstico em termos dos números de mortes relacionado à violência doméstica e familiar. Todavia a adoção do marco de aprovação da Lei Maria da Penha é importante, mesmo que de início possa se mostrar insuficiente tendo em vista que as formas de violência que são enfrentadas pela lei são as que se relacionam apenas à violência doméstica e familiar, pois aponta para novas investigações

2 Aliado a outros sistemas de informações como: os Censos Demográficos do Instituto Brasileiro de Geografia e Estatística (IBGE) e as estimativas intercensitárias disponibilizadas pelo Departamento de Informática do Sistema Único de Saúde (DATASUS); o Sistema de Informação de Agravos de Notificação (SINAN), do Ministério da Saúde; e a Pesquisa Nacional de Saúde (PNS). 
já que as características dos óbitos se mostram compatíveis com situações relacionadas a este tipo de violência (GARCIA et al., 2006; WAISELFISZ, 2015).

A preocupação do Estado em registrar dados que possibilitem a identificação violência doméstica e familiar por meio de seus sistemas de notificações é recente ${ }^{3}$, o que dificulta a análise sobre o aumento ou diminuição real desta violência na sociedade, considerando o marco da lei Maria da Penha. Todavia, como apontado acima, mesmo com a ausência de um parâmetro referencial concreto para a comparação dos dados relacionados ao aumento e a diminuição real da violência, pode-se realizar uma análise importante em conjunto com outras fontes, como as mudanças trazidas pela Lei Maria da Penha e os novos mecanismos e organismos de assistência e proteção às mulheres.

Dados governamentais e algumas pesquisas feitas em torno dos seus mecanismos, permitem afirmar que as mulheres passam a conhecer a possibilidade de denúncia (BRASIL, 2015c), assim como passam a utilizar dos mecanismos previstos em lei para sua proteção. De acordo com a Secretaria de Políticas para as Mulheres da Presidência da República, até o ano 2012 já haviam sido concedidas mais de 350 mil medidas protetivas (BRASIL, 2015b) e segundo o Instituto de Pesquisa Econômica Aplicada - IPEA (CERQUEIRA et al., 2015) a lei Maria da Penha fez diminuir em cerca de $10 \%$ a taxa de homicídio contra as mulheres ${ }^{4}$.

Esse maior acesso, como o que é feito em relação às medidas protetivas, apontam indícios de que as mulheres têm procurado

3 Apenas em 2003 foi estabelecida a notificação compulsória no caso de violência contra a mulher que for atendida em serviços de saúde públicos ou privados por meio da lei no.

$10.778 / 03$.

4 O relatório concluiu que do aumento do número de homicídios de mulheres verificados não se pode concluir sobre a não efetividade da lei e que pela pesquisa realizada, com base em metodologia de modelo de diferenças em diferenças, que confrontou os homicídios contra as mulheres dentro dos lares com aqueles que acometeram os homens, a LMP fez diminuir em cerca de $10 \%$ a taxa de homicídio contra as mulheres dentro das residências. 
mais o Estado para denunciar a violência, assim como possibilita compreender o porquê de os dados apontarem para um maior índice de violência contra as mulheres negras nessas notificações oficiais em comparação às mulheres brancas.

De acordo com o Mapa da Violência 2015 (WAISELFISZ, 2015) entre 2003 e 2013 o número passou de 3.937 para 4.762 homicídios de mulheres, o que indica um aumento de 21\% em dez anos. Só em 2013, os 4.762 casos de homicídios significaram uma média de 13 mulheres mortas por dia. Em relação ao marco da lei Maria da Penha, o relatório aponta que a maior parte desse aumento decenal aconteceu sob a égide da lei e que apesar do aumento das taxas, a partir de 2010 arrefece o ímpeto desse crescimento.

Para que se possa efetivamente entender o impacto da legislação, é necessário analisar como ela tem sido aplicada, pois sua eficácia depende do funcionamento das instituições e dos mecanismos em consonância com as determinações da lei. Como já mencionado, desde sua aprovação inúmeras denúncias têm sido realizadas em relação ao não cumprimento da lei pelo Poder Judiciário, o que indica a responsabilidade do Estado em relação a esse aumento.

É nessa linha de raciocínio que se dá a discussão aqui proposta, pois, se os dados revelam o aumento no número de homicídios, ele também aponta que dos 4.762 homicídios cometidos em 2013, mais de $50 \%$ foram de mulheres negras. Tal constatação contribui para a consolidação de dados que outras pesquisas e denúncias dos movimentos de mulheres negras já apontam há tempos, que as mulheres negras são mais violentadas e morrem mais que as mulheres brancas, e para o controle social das políticas públicas de prevenção e combate à violência contra as mulheres.

Outra análise promovida no relatório permite uma reflexão mais específica sobre o papel das instituições nesse contexto de violências, especialmente do Poder Judiciário: a proporção do aumento 
e da diminuição da violência quando da comparação entre o índice de homicídios das mulheres negras e das mulheres brancas. Segundo o relatório, a violência contra as mulheres brancas cai na proporção em que o índice em relação às mulheres negras cresce, os dados apontam que entre 2003 e 2013 há uma queda de 9,8\% no total de homicídios de mulheres brancas, enquanto os homicídios de mulheres negras aumentam 54,2\% no mesmo período (WAISELFISZ, 2015).

Apesar do aumento do homicídio de mulheres em termos gerais, a diminuição do homicídio de mulheres brancas num marco temporal em que houve a aprovação de uma lei específica de proteção ás mulheres é um indicativo de que há algum efeito positivo em termos de efetividade da lei, como já apontam outras pesquisas (CERQUEIRA et al., 2015). Mas em contraposição, o aumento de homicídios contra as mulheres negras no mesmo período e contexto fornece indicativos que apontam para outras reflexões no campo da efetividade da lei Maria da Penha.

Uma análise possível é a de que as mulheres brancas têm sido mais beneficiadas pelos mecanismos de proteção da LMP, enquanto que as mulheres negras não têm usufruído integral e efetivamente desses instrumentos. Como aponta Werneck (2010, p. 12), ignorar a presença e impacto do racismo, como o fazem algumas instituições, fortalece o privilégio racial das mulheres brancas e aprofunda das desigualdades entre as mulheres.

Os dados apontam para a necessária discussão em torno não só da opressão contra as mulheres negras no âmbito do Poder Judiciário, mas também em relação aos privilégios das mulheres brancas no acesso à justiça. A questão racial tem geralmente ficado a cargo das mulheres negras como se apenas elas fossem marcadas pela raça e é necessário que se compreenda que raça, assim como gênero, se constitui em relações de poder e, portanto, determina tanto a vida 
de mulheres e homens brancos como a de homens e mulheres negras (RIBEIRO, 1995).

As condições materiais de vida das mulheres negras são cotidianamente marcadas pelas dinâmicas excludentes do capitalismo, do racismo e do patriarcado e estes marcam profundamente a forma com que as instituições respondem às violências e exclusões por que passam. Para essa análise precisa-se partir de uma realidade, o comprometimento do Estado com ideologias racistas, sexistas e classistas (CRENSHAW, 2002; DALLARI, 2007; PIRES; LYRIO, 2016; PORTANOVA, 2003; SANTOS, 2013; WOLKMER, 2003). Significa dizer que, aliado a outros fatores de ordem social, política e econômica, o acesso aos mecanismos de proteção tem contribuído para a diminuição da violência contra as mulheres brancas, mas, em face do racismo institucional, tem aumentado esse índice em relação às mulheres negras.

$\mathrm{O}$ Estado tem negado o racismo, o que tem dificultado o enfrentamento real às violências sofridas pelas mulheres negras nas suas mais variadas dimensões. No Poder Judiciário vigoram ainda perspectivas que acompanharam a discussão da formação da sociedade brasileira e, dentre estas, a da democracia racial é a que tem impactos mais profundos na negativa do racismo como estruturante da vida social e na propagação da crença de que a sociedade brasileira é uma sociedade multirracial de classes (GUIMARÃES, 2003).

Juristas e magistrados têm historicamente resistido ao reconhecimento do racismo como crime e aos debates que se desdobram deste reconhecimento desde a aprovação da Constituição Federal de 1988 (SANTOS, 2013) e, mesmo com a previsão do crime de racismo no ordenamento jurídico brasileiro fruto das pressões do movimento negro, a ideologia da democracia racial ainda tem gerado impactos nas atuais decisões judiciais sobre a questão. Nesse sentido Pires e Lyrio (2016) destacam, como resultado de suas análises em 
processos judiciais relacionados à criminalização do racismo, que as decisões dos tribunais brasileiros são em sua maioria marcadas pela "cegueira da cor" e não consideram o fator raça em suas análises.

Os posicionamentos do Poder Judiciário em questões que envolvem os marcadores de raça, classe e gênero podem ser analisados sob o prisma da representatividade. Segundo o censo realizado pelo Conselho Nacional de Justiça (CNJ) em 2013, o Poder Judiciário é composto em sua maioria por homens (cerca de 64,1\%), brancos (apenas 5,1\% das mulheres que compõem a magistratura são negras e 10,5\% são homens negros) e de classe média/alta (CONSELHO NACIONAL DE JUSTIÇA, 2014).

Ao analisar esses dados em conjunto com outras pesquisas, Severi (2016) alerta para a necessidade de aprofundamento das análises sobre a relação entre a representatividade e a produção de decisões mais justas, pois, no marco da interseccionalidade, é preciso atentar para o fato de que mesmo num contexto de pouca representatividade na magistratura, quando esta é constatada, percebe-se que a heterogeneidade tende a desaparecer frente a uma identidade profissional do que é ser juiz e juíza, marcada por elementos específicos de um ethos atrelado ao gênero masculino, branco e heterossexual. Todavia, mesmo que não se possa confirmar a hipótese de que a diversidade de gênero e raça/etnia na composição do Judiciário resultaria necessariamente em decisões mais justas, a autora ressalta a importância da representatividade enquanto democratização do Sistema de Justiça e uma atuação efetiva no campo da defesa dos direitos humanos.

A forma com que o Poder Judiciário trata historicamente as denúncias de racismo e de violência contra as mulheres e sua composição majoritariamente de homens brancos não devem ser

5 Segundo as autoras: “a ideia de cegueira a cor está ancorada na mistificação da igualdade formal e na crença de que tratamentos diferenciados entre bancos e negros geraria um "racismo às avessas" (PIRES; LYRIO, 2016, p. 3). 
entendidas como coincidência, mas como parte do processo histórico e político que marca a construção do Estado brasileiro e que demonstra a ausência de vontade política em combater essas exclusões, deixando nítido o fato de que este é dominado por grupos raciais específicos.

A invisibilização da questão racial pelo Poder Judiciário tem fortes impactos, pois a inexistência de fontes relevantes que possam dar subsídios para a análise se reflete na própria escassez de estudos que problematizem os dados referente à raça/etnia tanto na composição da magistratura como nas análises sobre racismo institucional e a cultura judiciária (SEVERI, 2016).

Werneck(2010),nessesentido, destacaqueéprecisocompreender que o racismo participa das escolhas e dos mecanismos de políticas públicas e impede a elaboração de respostas adequadas à superação das violências e da exclusão dos grupos racialmente inferiorizados, participando dos objetivos, dos modos de funcionamento e resultados das políticas públicas. Diante desse quadro, a questão que se coloca é, como o Poder Judiciário pode atuar no campo do combate à violência doméstica e familiar contra as mulheres negras, se institucionalmente não reconhece a raça como um marcador de diferenças e desigualdade ou o racismo como um sistema de opressão?

O mito da democracia racial ainda tem fortes impactos na invisibilidade da questão junto ao Poder Judiciário e influencia consideravelmente a recusa deste em olhar de forma mais atenta para as mulheres negras no âmbito da violência doméstica e familiar. $\mathrm{O}$ Poder Judiciário é branco, macho e rico e a sociedade é negra, pobre e feminina. Como falar em uma atuação que considere essas questões diante posicionamentos políticos, sociais e econômicos opostos? Com esses privilégios é possível que a atuação do Poder Judiciário seja efetiva no combate à violência doméstica e familiar contra as mulheres negras? Estes são questionamentos importantes para as reflexões acerca da prevenção da violência e da proteção das mulheres negras e 
mesmo que não tenhamos respostas concretas, uma coisa está nítida, é preciso enegrecer o Poder Judiciário.

\section{REFERÊNCIAS}

BRASIL. Ministério da Justiça. Secretaria de Assuntos Legislativos. Violências contra a mulher e as práticas institucionais. Brasília: Ministério da Justiça, 2015a.

BRASIL. Secretaria de Políticas para as Mulheres da Presidência da República. Lei Maria da Penha já gera mais de 350 mil medidas protetivas. Disponível em: <www. brasil.gov.br/cidadania-e-justica/2013/09/lei-maria-da-penha-ja-gera-mais-de-350mil-medidas-protetivas $>$. Acesso em 27 ago. 2015b.

BRASIL. Senado Federal. Relatório final da Comissão Parlamentar Mista de Inquérito (CPMI da Mulher). Disponível em: <http://www.senado.gov.br/atividade/materia/ getPDF.asp?t=130748\&tp=1>. Acesso em: 21 ago. 2014.

BRASIL. Senado Federal. Violência doméstica e familiar contra a mulher: pesquisa de opinião pública nacional. Disponível em: <www.senado.gov.br/noticias/ opiniaopublica>. Acesso 17 ago. 2015c.

CARNEIRO, Sueli. Mulheres em movimento. Estudos Avançados, São Paulo, v. 17, n. 49, p. 117-133, Dec. 2003.

CARVALHO, Rayssa Andrade; ROCHA, Solange Pereira da. Feminismo negro no Brasil: ações da Bamidelê - organização de mulheres negras na Paraíba na construção e afirmação de identidade negra. In: ENCONTRO NACIONAL DA REDE FEMINISTA E NORTE E NORDESTE DE ESTUDOS E PESQUISA SOBRE A MULHER E RELAÇÕES DE GÊNERO, 17., 2012, João Pessoa. Anais... João Pessoa: UFPB, 2012. p. 361-377.

CERQUEIRA, Daniel et al. Avaliando a efetividade da lei Maria da Penha. Brasilia: IPEA, 2015. Disponível em: <http://www.ipea.gov.br/portal/images/stories/PDFs/ TDs/ td_2048.pdf $>$. Acesso em 20 maio 2016.

CONSELHO NACIONAL DE JUSTIÇA. Censo do poder judiciário: Vide: Vetores Iniciais e Dados Estatísticos. Brasília: CNJ, 2014.

COSTA, Sérgio. Dois atlânticos: teoria social, anti-racismo, cosmopolitismo. Belo Horizonte: UFMG, 2006.

CRENSHAW, Kimberlé. Documento para o encontro de especialistas em aspectos da discriminação racial relativos ao gênero. Revista Estudos Feministas, Florianópolis, v. 10, n. 1, p. 171-188, 2002.

DALLARI, Dalmo de Abreu. O poder dos juízes. São Paulo: Saraiva, 2007. 
FERREIRA, Anadilza Maria Paiva; BARBOSA, Luciana Cândido; OLIVEIRA, Tatyane Guimarães. Mulheres em situação de violência: olhares feministas sobre a Rede de Atendimento. Cunhã - Coletivo Feminista. João Pessoa: Ideia, 2015.

GARCIA, Leila Posenato et al. Violência contra a mulher: feminicídio no Brasil. Disponível em: <http://www.ipea.gov.br/portal/images/stories/PDFs/130925_sum_ estudo_feminicidio_leilagarcia.pdf $>$. Acesso em: 20 maio 2016.

GOMES, Márcia Queiroz de Carvalho. Projeto: construção e implementação do Observatório da Lei 11.340/2006 - Lei Maria da Penha. Relatório Final. Salvador: Observe, 2009.

GUIMARÃES, Antonio Sérgio Alfredo. Como trabalhar com "raça" em sociologia. Educação e Pesquisa, São Paulo, v. 29, n. 1, p. 93-108, 2003.

MUNANGA, Kabengele. Uma abordagem conceitual das noções de raça, racismo, identidade e etnia. Cadernos PENESB, Rio de Janeiro, n. 5, p. 15-34, 2004.

PASINATO, Wânia. Juizados especiais de violência doméstica e familiar contra a mulher e a rede de serviços para atendimento de mulheres em situação de violência em Cuiabá, Mato Grosso. 2009. Disponível em: <http://www.observe. ufba.br/_ARQ/estudodecaso.pdf>. Acesso em 22 abr. 2014.

PEREIRA, Bruna Cristina Jaquetto. Tramas e dramas de gênero e cor: a violência doméstica e familiar contra mulheres negras. Dissertação (Mestrado em Sociologia) - Instituto de Ciências Sociais, Universidade de Brasília, Brasília, 2013.

PIRES, Thula Rafaela de Oliveira; LYRIO, Caroline. Racismo institucional e acesso à justiça: uma análise da atuação do Tribunal de Justiça do Estado do Rio de Janeiro nos anos de 1989-2011. Disponível em: <http://www.publicadireito.com.br/artigos/? cod=7bf570282789f279>. Acesso em 16 jun. 2016.

PORTANOVA, Rui. Motivações ideológicas da sentença. Porto Alegre: Livraria do Advogado, 2003.

RIBEIRO, Matilde. Mulheres negras brasileiras, de Bertioga a Beijing. Estudos Feministas, Rio de Janeiro, v. 3, n. 2, p. 446-57, 1995.

SAFFIOTI, Heleieth. Gênero, patriarcado, violência. 2. ed. São Paulo: Expressão Popular; Fundação Perseu Abramo, 2015.

SANTOS, Ivair Augusto Alves dos. Direitos humanos e as práticas de racismo. Brasília: Câmara dos Deputados; Edições Câmara, 2013.

SARDENBERG, Cecilia M. B. Caleidoscópios de gênero: gênero e interseccionalidades na dinâmica das relações sociais. Mediações: Revista de Ciências Sociais, Londrina, v. 20, n.2, p. 56-96, jul./dez. 2015. 
SCAVONE, Lucila. Estudos de gênero: uma sociologia feminista? Revista Estudos Feministas, Florianópolis, v. 16, n. 1, p. 173-186, jan./abr. 2008.

SCOTT, Joan Wallach. Gênero: uma categoria útil para a análise histórica. Educação e Realidade, Porto Alegre, v. 16, n. 2, p. 5-22, jul./dez. 1990.

SCOTT, Joan Wallach. O enigma da igualdade. Revista Estudos Feministas, Florianópolis, v. 13, n. 1, p. 11-30, jan./abr. 2005.

SEVERI, Fabiana Cristina. O gênero da justiça e a problemática da efetivação dos direitos humanos das mulheres. Revista Direito e Práxis, Rio de Janeiro, v. 7, n. 13, p. 81-115, 2016.

WAISELFISZ, Julio Jacobo. Mapa da violência 2015: homicídio de mulheres no Brasil. Brasília: Flacso, 2015.

WERNECK, Jurema. Mulheres negras e violência no Rio de Janeiro. In: CASTRO, Lúcia Maria Xavier de; CALASANS, Myllena; REIS Sarah. Mulheres de Brasília e do Rio de Janeiro no monitoramento da política nacional de enfrentamento à violência contra as mulheres. Rio de Janeiro: CRIOLA; CFEMEA, 2010. p. 11-50.

WOLKMER, Antonio Carlos. Ideologia, Estado e direito. 4. ed. São Paulo: Revista dos Tribunais, 2003. 